\title{
Relationship between Religiosity and the Tendency toward Voluntary Participation in the Activities of the Red Crescent Society in Isfahan
}

\section{Seyed Morteza Emadi ${ }^{1} \mathbb{D}$, Gholamreza Jafarinia $^{2} \mathbb{D}$, Nasser Amini $^{3} \mathbb{C}$}

Date of submission: 18 Aug. 2020 Date of acceptance: 13 Oct. 2020

\begin{abstract}
INTRODUCTION: Social participation has proved to be effective in the establishment and development of civil societies, assuming great importance in this regard. The Red Crescent Society, as the largest non-governmental organization (NGO) in the country and the oldest NGO in the world, is engaged in humanitarian activities at both national and international levels through attracting and retaining volunteers and public participation.

METHODS: The present practical quantitative cross-sectional field study aimed to investigate the relationship between religiosity and citizens' voluntary participation in the activities of the Red Crescent Society. The statistical population included all volunteers participating in the activities of the Isfahan Red Crescent Society, out of whom 384 cases were selected as the sample. The data were analyzed using SPSS software and structural equation modeling in SmartPLS software.

FINDINGS: It can be seen that religiosity in various dimensions is one of the important sources of increasing the voluntary participation of citizens, which increases the various dimensions of voluntary participation. In this regard, it can be said that Islam especially Shia religion due to its collective nature of abundance can play a very important role in increasing the voluntary participation of citizens and the Red Crescent Society, as a non-profit public institution, can also use this capacity to advance its transcendent goals.

CONCLUSION: As evidenced by the obtained results, there was a positive and significant relationship between religiosity dimensions (belief, experience, practice, knowledge, and consequences) and voluntary participation in the activities of the Red Crescent Society; therefore, all research hypotheses were confirmed. Furthermore, based on the results of the structural equation model (SmartPLS), religiosity had a moderate effect on voluntary participation in the activities of the Red Crescent Society.
\end{abstract}

Original Article

Keywords: Red Crescent Society; Religiosity; Social Participation; Voluntary Participation.

How to cite this article: Emadi SM, Jafarinia G, Amini N. Relationship between Religiosity and the Tendency toward Voluntary Participation in the Activities of the Red Crescent Society in Isfahan. Sci J Rescue Relief 2020; 12(3): 177-184.

\section{Introduction}

$\mathrm{N}$ ational development in third world countries heavily depends on active participation and effective social harmony of citizens. Lack of this engagement provides grounds for conflicts and contradictions among different sectors (private and public) of the community. Therefore, policymakers and planners should focus on highlighting the role of public participation in the development process, especially in the social, political, and economic fields (1). Through delegation of some responsibilities to local organizations, the central organs of the government can shift their focus towards the key problems of the country; moreover, they can develop national plans and monitor them.

1-PhD student, Sociology, Bushehr Branch, Islamic Azad University, Bushehr, Iran

2-PhD, Department of Sociology, Bushehr Branch, Islamic Azad University, Bushehr, Iran

3-PhD, Department of Psychology, Bushehr Branch, Islamic Azad University, Bushehr, Iran

Correspondence to: Gholamreza Jafarinia,Email: Jafarinia_reza@yahoo.com,sm1357.emadi@gmail.com 
Strengthening local organs and organizations in a state of decentralization is one of the efficient strategies to increase participation and social harmony in social, administrative, civil, and political issues (2). One of the manifestations of voluntary public participation is engagement in the activities of the Red Crescent Society. Attracting and retaining volunteers and public participation is of such importance that all the activities of the Red Crescent Society are defined accordingly (3).

The strategies used to attract participation have a profound impact on volunteering in the Red Crescent Society. Bases on the specific circumstances of the groups, as well as the specific cultural characteristics and available facilities, it is possible to provide the grounds for attracting both individuals and groups to participate in voluntary activities. In this regard, religiosity is among the factors which increase citizens' engagement in Red Crescent activities.

Religion as the cornerstone of social order and a source of social values affects individual choices and numerous aspects of daily life. It is also deemed as the manifestation of the collective spirit and an influential factor affecting solidarity and unity of society (4). Today, the achievement of sustainable and effective development is one of the factors with a special place in the micro and macro planning of every country. In this process, it is highly recommended that governments and government organizations use the potentials of NGOs to achieve sustainable development.

Consequently, these organizations have recently expanded; moreover, in Iran, the transfer of government responsibilities to nongovernmental sectors has been one of the main programs of governments in recent years. Accordingly, in the new laws and regulations on crisis management of the country, the Red Crescent Society, as the government's deputy for relief and rescue, is in charge of responding to emergencies.

Therefore, in light of the aforementioned issues, the present study sought to assess the relationship between religiosity and the tendency for voluntary participation in the activities of the Red Crescent population in Isfahan. Here, some conducted studies in this regard are discussed.

Muhammad Saleh et al conducted a study entitled "Investigating the factors affecting women's participation in voluntary activities". Adopting a descriptive-analytical method, the mentioned research examined and explained the impacts of such factors as emotions, family, upbringing, education, age, literacy, economic law, and religious factors in five domains: individual, family, economic, social, and religious (5). The results of a study entitled "Examining the role of religiosity in the trust and social participation of students of Lorestan University" showed that social trust had a positive and significant effect on students' social participation (6).

Another study which was performed in this field entitled "Assessing the role of social capital on group participation of youth in the activities of the Red Crescent Society". The results of the referred study demonstrated that the mean scores of participation in-group activities of the Red Crescent Society and the dimensions of the social capital variable were less than the assumed mean, indicating that these variables are not in a favorable situation among the study population. The results also denoted that social belonging and trust were the most important variables affecting participation in-group activities of the Red Crescent Society among the young people aged 21-29 in Tehran (7).

"Investigating the role of public participation in improving crisis management in the Red Crescent Organization" is the title of another research conducted in Chaharmahal and Bakhtiari province. The results of the stated study disclosed the effect of the participation of citizens and government officials in the management of flood crisis before the occurrence of flood. Therefore, the non-structural factor of public participation performs a more significant role in flood management, compared to structural factors (8).

"Socio-political participation and social factors affecting it" is the title of a study conducted by researchers in Khodabandeh. The findings of the referred study pointed to moderate to low socio-political participation in Khodabandeh. Moreover, a significant correlation was detected between independent variables (e.g., age, gender, social class, place of residence, populism, futurism, socio-political alienation, trust, family structure, education, mass media, and fatalism) and the dependent variable (sociopolitical participation) (9).

In the same context, Vichela carried out a study entitled "Cambodian women and barriers to social participation" and reported the cultural factors as the main obstacle to women's participation. $\mathrm{He}$ 
believes that women are considered to be endowed with such characteristics as decency, conscientiousness, restraint, and honesty towards their parents. Therefore, owing to these cultural pressures, Cambodian women follow cultural values without any knowledge and awareness (10).

In their study on 2667 subjects, Bahry et al. investigated the participation of Russian citizens in the Gorbachev era. The findings of the mentioned study pointed out that social activity depends on people's motivations. They reported that critical citizens who are satisfied with their lives are more likely to be social activists. Nonetheless, political motives are less important to them, they are not interested in politics, and do not support government control over civil and economic freedoms (11).

Uslaner et al. performed a study on inequality, trust, and civic engagement using US state-level data in the 1970s, 1980s, and 1990s. They reported that inequality leads to distrust, which in turn, indirectly affect participation (12). Along the same lines, another study assessed the relationship between religion and participation among religious groups in the United States. The results of this study showed that the level of participation significantly differed among religious groups. Jewish participants were more involved in various activities, compared to Christians, and among Christians, moderators and modernists were more active than secular groups. The level of group participation also depended on other factors, such as family patterns, level of religious affiliation, interests, and awareness of individuals. The results of the mentioned study indicated a positive relationship between religious beliefs and participation (13).

\section{Theoretical and experimental framework of research}

In the present study, various theories were used as theoretical foundations; nonetheless, a number of theories that were the basis of hypothesis extraction form the theoretical framework of the study. According to the theory proposed by Glock and Stark, religiosity has been examined in various dimensions: belief, consequence, practice, experience, and knowledge. Almond and Verba (1963)'s structural-functionalist theory emphasizes structural diversity, religious culture, and the high level of independence of subsystems.

Furthermore, they believe in expediency, the preference of collective activities over individualism, the degree of solidarity, and compliant attitudinal orientation toward the political system (14). A study entitled "Religion, gender, and political participation in Africa" assessed the relationship between religious attitudes (Islam and Christianity) and the level of political participation in Nigeria, Uganda, and Senegal. The mentioned study which was conducted on 3,600 subjects suggested that people with religious orientation are at a high cognitive level, and religion has a significant impact on the political activities of these people.

In addition, it was found that both Islam and Christianity promote people to participate in social affairs; however, the level of engagement was higher among Muslims, as compared to Christians (15). Therefore, based on the theory proposed by Almond, Verba, and Fukuyama, as well as the studies conducted by Guth and al, as well as Hoffman and Dowd, the following hypothesis was extracted: There is a significant relationship between participation and religiosity in different dimensions. Moreover, according to Glock and Stark's theory about different dimensions of religiosity (belief, experience, practice, knowledge, and consequences), these sub-hypotheses were extracted:

There is a relationship between citizen participation and different dimensions of religiosity (belief, consequences, religious practice, knowledge, and experience).

The research hypotheses are as follows:

- There is an association between religiosity and the voluntary participation of citizens in the activities of the Red Crescent Society.

- There is a relationship between the voluntary participation of citizens in the activities of the Red Crescent Society and the dimension of belief.

- There is a relationship between the voluntary participation of citizens in the activities of the Red Crescent Society and the dimension of consequences.

- There is a relationship between the voluntary participation of citizens in the activities of the Red Crescent Society and the dimension of religious practice.

- There is a relationship between the voluntary participation of citizens in the activities of the Red Crescent Society and the dimension of experience.

- There is a relationship between the voluntary 
participation of citizens in the activities of the Red Crescent Society and the dimension of knowledge.

\section{Methods}

The present practical quantitative crosssectional field study aimed to investigate the relationship between religiosity and citizens' voluntary participation in the activities of the Red Crescent Society. In this field study, a questionnaire was used to collect the required information. The researcher-made questionnaire was initially tested before the survey and using the results, the existing deficiencies were corrected, and the final questionnaire was developed. It is noteworthy that the questionnaire used for religiosity was based Glock and Stark theory about different dimensions of religiosity (belief, experience, practice, knowledge, and consequences).

The statistical population of the present study included all volunteers participating in the activities of the Red Crescent Society of Isfahan $(n=15,000)$. Since it was not possible to assess the views of all residents, the sample sized was calculated at 384 subjects using Cochran's formula:

$$
\begin{aligned}
& N=15000 \quad t=1 / 96 P=0 / 5 \quad q=0 / 5 \quad d=0 / 04 \\
& n=\frac{\frac{(1 / 96)^{2} \times(0 / 5)(0 / 5)}{(0 / 04)^{2}}}{1+\frac{1}{15000}\left(\frac{(1 / 96) \times(0 / 5)(0 / 5)}{(0 / 04)^{2}}-1\right)}=384 \\
& n=\frac{\frac{t^{2} p q}{d^{2}}}{1+\frac{1}{N}\left(\frac{t^{2} p q}{d^{2}}-1\right)}
\end{aligned}
$$

The sampling method was performed in two steps. Firstly, a number of neighborhoods in Isfahan were selected, and the final sample was extracted from each neighborhood in the second stage. After collecting the data, they were analyzed in SPSS and Smart PLS software using statistical tests appropriate to each hypothesis. In this regard, to ensure the required validity, professors and experts in this field were consulted; moreover, Cronbach's alpha test was used to assess the reliability of the questionnaire rendering a coefficient of $>0.7$ for all variables.

Table 1. Reliability of the final questionnaire based on Cronbach's alpha coefficient

\begin{tabular}{|c|cc|} 
Variable & Indicator & $\begin{array}{c}\text { Cronbach's } \\
\text { alpha coefficient }\end{array}$ \\
\hline \multirow{3}{*}{ Religiosity } & Belief & 0.852 \\
& Consequences & 0.793 \\
& Practice & 0.842 \\
& Experience & 0.721 \\
& Knowledge & 0.725 \\
Voluntary & Environmental & \\
participation & Health and wellbeing & 0.825 \\
& activities & 0.814 \\
& Support activities & 0.754 \\
& Relief activities & 0.777 \\
\hline
\end{tabular}

\section{Findings}

\section{Descriptive Statistics}

Based on frequency results, $60.16 \%$ of the subjects were male and the other $39.84 \%$ were female. Regarding marital status, $59.90 \%$ of the subjects were married and the other $40.10 \%$ were single. In terms of education, $23 \%, 28 \%, 40 \%$, and $9 \%$ of the respondents had high school and diploma, an associate degree, a bachelor's degree, and a master's degree and higher, respectively. Furthermore, the age distribution of subjects was as follows: $18-20=16 \%, 25-29=21 \%, 30$ $35=21 \%, 35-40=15 \%, 40-49$ years $=16 \%, 50-$ $60=8 \%$, and over 60 years old $=3 \%$.

Based on the results, among the indicators of religiosity, belief (90.83) and practice (65.61)

\begin{tabular}{|c|c|c|c|c|c|c|c|c|c|c|}
\hline \multirow{2}{*}{$\begin{array}{c}\text { Dimensions } \\
\text { of } \\
\text { religiosity }\end{array}$} & \multirow{2}{*}{$\begin{array}{c}\text { Belief } \\
\text { Frequency }\end{array}$} & \multicolumn{2}{|c|}{ Consequences } & \multicolumn{2}{|c|}{ Practice } & \multicolumn{2}{|c|}{ Experience } & \multicolumn{3}{|c|}{ Knowledge } \\
\hline & & Percentage & Frequency & Percentage & Frequency & Percentage & Frequency & Percentage & Frequency & \\
\hline Very low & 8 & 95.08 & 17 & 64.42 & 51 & 62.17 & 14 & 65.42 & 16 & 61.28 \\
\hline Low & 14 & 91.65 & 33 & 71.34 & 66 & 61.61 & 26 & 69.34 & 48 & 69.64 \\
\hline Moderate & 95 & 85.74 & 99 & 62.78 & 121 & 57.51 & 108 & 60.78 & 127 & 60.33 \\
\hline High & 144 & 89.50 & 166 & 71.23 & 100 & 61.71 & 160 & 70.23 & 131 & 69.04 \\
\hline Very high & 124 & 82.03 & 70 & 57.23 & 64 & 50.98 & 76 & 55.23 & 63 & 55.15 \\
\hline Total & 384 & 100 & 384 & 100 & 384 & 100 & 384 & 100 & 384 & $` 100$ \\
\hline Mean & 90.83 & \multicolumn{2}{|c|}{71.16} & \multicolumn{2}{|c|}{65.61} & \multicolumn{2}{|c|}{70.16} & \multicolumn{3}{|c|}{69.38} \\
\hline
\end{tabular}
dimensions had the highest and lowest means,

Table 2. Distribution of respondents by religiosity 
Table 3. Distribution of respondents according to voluntary participation and its dimensions

\begin{tabular}{|c|c|c|c|c|c|c|c|c|}
\hline \multirow{2}{*}{$\begin{array}{l}\text { Components } \\
\text { of voluntary } \\
\text { participation }\end{array}$} & \multicolumn{2}{|c|}{ Environmental } & \multicolumn{2}{|c|}{ Health and wellbeing } & \multicolumn{2}{|c|}{ Support } & \multicolumn{2}{|c|}{ Relief } \\
\hline & Frequency & Percentage & Frequency & Percentage & Frequency & Percentage & Frequency & Percentage \\
\hline Very low & 29 & 84.55 & 56 & 90.58 & 24 & 73.10 & 42 & 94.6 \\
\hline Low & 72 & 86.29 & 67 & 90.46 & 34 & 71.8 & 79 & 90.57 \\
\hline Moderate & 113 & 71.42 & 138 & 80.93 & 114 & 62.32 & 174 & 85.31 \\
\hline High & 86 & 77.51 & 71 & 81.09 & 161 & 71.28 & 59 & 88.96 \\
\hline Very high & 84 & 71.23 & 52 & 78.94 & 51 & 58.23 & 50 & 80.22 \\
\hline Total & 384 & 100 & 384 & 100 & 384 & 100 & 384 & 100 \\
\hline Mean & \multicolumn{2}{|c|}{81.83} & \multicolumn{2}{|c|}{87.13} & \multicolumn{2}{|c|}{72.78} & \multicolumn{2}{|c|}{89.94} \\
\hline
\end{tabular}

respectively. Furthermore, the means of consequences, knowledge, and experience were obtained at 71.16, 69.38, and 70.16, respectively. The total mean score of religiosity was reported as 73.42, signifying above average and almost high level of religiosity of the participants. Nonetheless, the point worth noting about the religiosity of the respondents was the low level of religious practices despite the desirable level of religious beliefs. That is to say, the participants had strong religious beliefs; however, they performed the rituals less frequently.

Moreover, it was found that among the indicators of voluntary participation in Red Crescent activities, relief (89.94) and environmental activities (81.83) had the highest and lowest means. Moreover, the mean scores of participation in health/wellbeing activities and supportive activities were obtained at $87 / 13$ and 72.78 , respectively. The total mean score of voluntary participation was reported as 82.92, indicating that respondents' participation was above average.

\section{Inferential statistics}

\section{Assessing the normal distribution of data}

There are prerequisites for using parametric tests, including the normality of data, which is assessed by the one-sample Kolmogorov-Smirnov test as follows:

$\mathrm{H}_{0}$ : Data are normally distributed.

$\mathrm{H}_{1}$ : Data are not normally distributed.

As illustrated in Table 4, the significance level of all research variables is more than 0.05 , indicating the normality of data distribution. Therefore, parametric tests can be used to analyze the research hypotheses.

\section{Testing hypotheses}

There is a relationship between the citizens' voluntary participation in the activities of the Red Crescent Society with different dimensions of religiosity (belief, experience, practice, knowledge, and consequences). As displayed in Table 5, the Pearson correlation coefficient test was used to assess the relationship between citizens' voluntary participation in the activities of the Red Crescent Society with different dimensions of religiosity (belief, experience, practice, knowledge, and consequences).

The findings pointed to a positive and significant relationship between citizens' voluntary participation in the activities of the Red Crescent Society and all dimensions of religiosity. Moreover, dimensions of belief $(\mathrm{P}=0.40)$ and knowledge $(\mathrm{P}=0.24)$ had the highest and lowest correlation with citizens' engagement in the activities of the Red Crescent Society, respectively. Moreover, the dimensions of practice $(\mathrm{P}=0.35)$, consequence $(\mathrm{P}=0.30)$, and experience $(\mathrm{P}=0.26)$ had a positive and significant correlation coefficient. Therefore, it can be argued that engagement in the activities of the Red Crescent Society was higher among the people with higher levels of religiosity $(\mathrm{P}=0.34)$; therefore, all the hypotheses of the present study were confirmed.

Table 4. Kolmogorov-Smirnov test to determine the normality of research variables

\begin{tabular}{|c|c|c|c|c|c|c|}
\hline $\begin{array}{l}\text { Subscales } \\
\text { Indicators }\end{array}$ & Belief & Consequences & practice & Experience & Knowledge & $\begin{array}{c}\text { Voluntary } \\
\text { participation }\end{array}$ \\
\hline $\mathrm{N}$ & 384 & 384 & 384 & 384 & 384 & 384 \\
\hline Kolmogorov-Smirnov values & 2.70 & 2.98 & 2.54 & 3.01 & 3.60 & 2.12 \\
\hline Significance level (two ranges) & 0.088 & 0.12 & 0.097 & 0.083 & 0.16 & 0.23 \\
\hline
\end{tabular}


Table 5. Correlation between independent and dependent variables of research

\begin{tabular}{|c|c|c|c|}
\hline \multirow{2}{*}{\multicolumn{2}{|c|}{ Indicator }} & \multicolumn{2}{|c|}{$\begin{array}{l}\text { Variable } \\
\text { Volunteering in the Red Crescent Society }\end{array}$} \\
\hline & & Correlation coefficient & Significance level \\
\hline \multirow{6}{*}{ Religiosity } & Belief & 0.40 & 0.000 \\
\hline & Consequences & 0.30 & 0.000 \\
\hline & Practice & 0.35 & 0.000 \\
\hline & Experience & 0.26 & 0.001 \\
\hline & Knowledge & 0.24 & 0.002 \\
\hline & Total & 0.34 & 0.000 \\
\hline
\end{tabular}

\section{Structural Equation Model using the software SmartPLS}

A structural equation model was used to determine the intensity of the association and assess the effect of different dimensions of religiosity on voluntary participation in the activities of the Red Crescent Society. In this research, structural equation modeling which was performed in two stages was used to test research hypotheses. This implies that after developing the theoretical model of the research, it is necessary to obtain estimates of the model or free parameters and analyze indicators of the model in an attempt to determine whether the experimental data support the theoretical model.

Unlike the covariance-based SEM techniques (such software as AMOS, LISREL, and EQS), Partial least squares (PLS) path modeling does not provide chi-square goodness-of-fit indices to check the conformity of the theoretical model with the collected data. This depends on the predictive nature of the PLS axis. Therefore, the fit indices developed with this approach are related to the assessment of model adequacy to predict dependent variables, such as communality, redundancy, or goodness of fit (GOF) indices.

In fact, these indices demonstrated to what extent they can predict their underlying structure. Moreover, they indicate how well exogenous variables of the model can predict endogenous variables. The estimates of the structural model and its main parameters (the effect of religiosity variable on voluntary participation in the activities of the Red Crescent Society) are displayed in the following figures and tables:

In general, these indices show that the data support the theoretical model of the research; in other words, the data fit into the model, and the indices support the fitness of the structural equation model.

The values estimated in the abovementioned table above point to the following issues:

1) The variable of religiosity explains 0.455
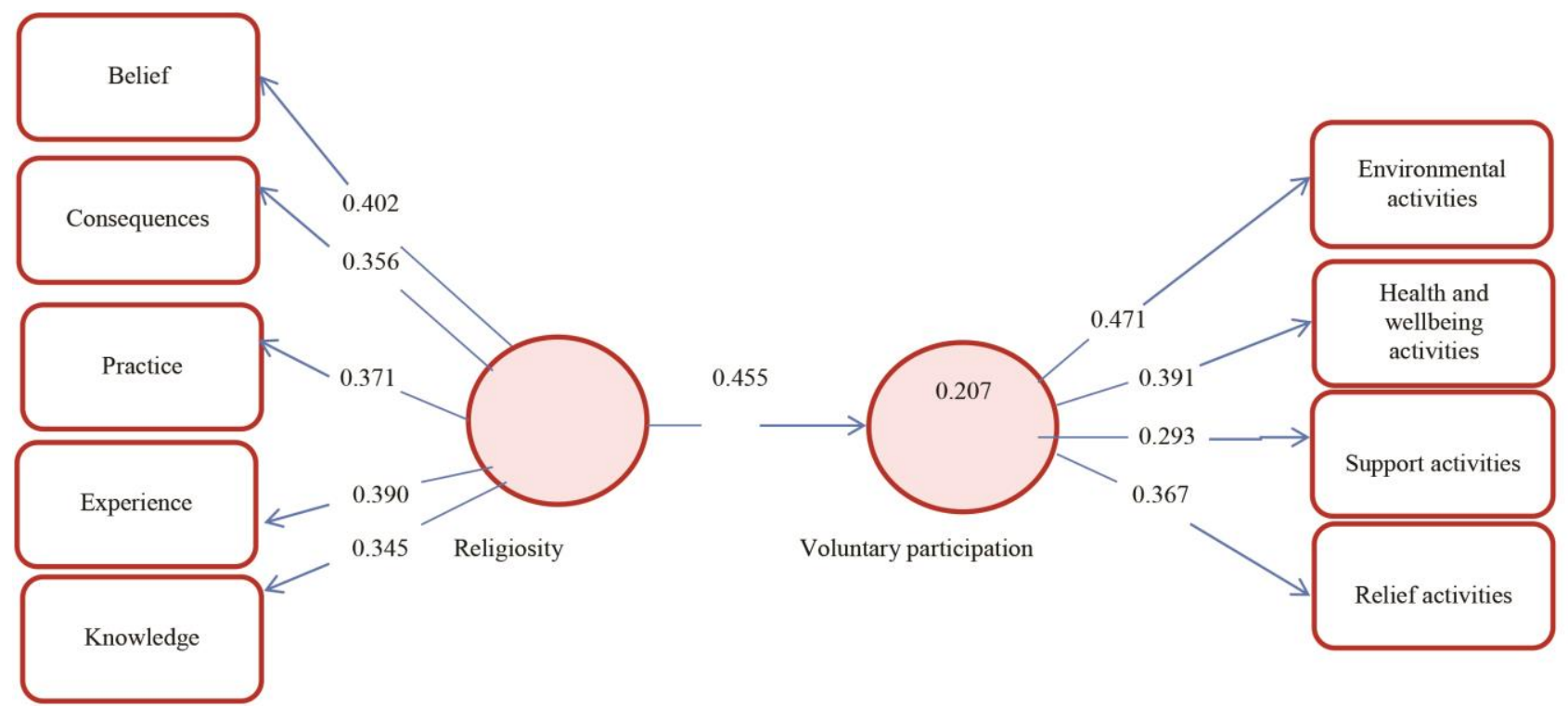

Figure 1. Structural equation model of the effect of religiosity on voluntary participation in the activities of the Red

Crescent Society 
Table 6. Estimates of the structural model

\begin{tabular}{|c|c|c|c|}
\hline Index & GOF & SRMR & NFI \\
\hline Value & 0.80 & 0.085 & 0.92 \\
\hline
\end{tabular}

of the variance of voluntary participation in the activities of the Red Crescent Society. Considering the values of effect size, the coefficient of determination was estimated to be average $(0.20)$. In other words, the variable of religiosity in different dimensions had the ability to explain the variance of citizens' voluntary participation in the activities of the Red Crescent Society.
2. Religiosity had a significant effect on voluntary participation in the activities of the Red Crescent Society. Therefore, the main general research hypothesis" Religiosity affects voluntary participation in the activities of the Red Crescent Society" was confirmed. Considering the value of the impact coefficient, it can be concluded that religiosity has a positive and moderate effect on voluntary participation in the activities of the Red Crescent Society. This signifies that a moderate increase in religiosity can promote voluntary participation in the activities of the Red Crescent Society.

Table 7. Estimating the effect of religiosity on voluntary participation in the activities of Red Crescent Society

\begin{tabular}{ccccccc|}
$\begin{array}{c}\text { Independent } \\
\text { variable }\end{array}$ & Path $\mid$ & Dependent variable & $\begin{array}{c}\text { Coefficient of } \\
\text { Determination }\end{array}$ & $\begin{array}{c}\text { Coefficient } \\
\text { of effect size }\end{array}$ & $\begin{array}{c}\text { Critical } \\
\text { value }\end{array}$ & $\begin{array}{c}\text { Significance } \\
\text { level }\end{array}$ \\
\hline Religiosity & $<---$ & Voluntary participation & 0.207 & 0.455 & $1 / 2$ & 0.001 \\
\hline
\end{tabular}

\section{Discussion and Conclusion}

As mentioned earlier, although volunteering in humanitarian services and citizen participation has been always necessary, the current situation of the world has proved an urgent need for this engagement, both at national and international levels. Therefore, in recent decades, different countries have shifted their focus toward participatory democracy, participatory development, and participatory measures in a neighborhood, and regard them as the key to solving some of the problems of their society.

One of the important domains of voluntary citizen engagement is participation in the activities of the Red Crescent Society, which was discussed in the present study. Given the importance of the relationship between religiosity and participation in the activities of the Red Crescent Society, the present study was conducted on 384 volunteers to assess the association between this engagement and different dimensions of religiosity (belief, experience, practice, knowledge, and consequences). The obtained results disclosed a positive and significant relationship between all dimensions of religiosity and voluntary participation in the activities of the Red Crescent Society.

Moreover, it was found that dimensions of belief and knowledge had the highest and lowest correlation with citizens' engagement in the activities of the Red Crescent Society, respectively. Therefore, it can be argued that engagement in the activities of the Red Crescent Society was higher among the people with higher levels of religiosity $(\mathrm{P}=0.34)$; therefore, all the hypotheses of the present study were confirmed. The results of structural equation modeling using SmartPLS software also showed that religiosity had a moderate effect on participation in the activities of the Red Crescent Society. Moreover, the variable of religiosity explained the variance of voluntary participation in the activities of the Red Crescent Society.

The findings of the present study on the relationship between religiosity and participation are consistent with those obtained by Mousavi et al., Nowruz and Bakhtiari, Hoffman and Dowd, and Vicheka who assessed the association between religiosity and participation. Therefore, it is observed that religiosity in different dimensions is one of the major boosters of citizens' voluntary participation. In this regard, it can be concluded that the religion of Islam, especially Shiite, due to its collective nature can perform a peculiar role in boosting citizens' voluntary participation. Moreover, the Red Crescent Society as a humanitarian institution can benefit from this capacity to attain its transcendent goals

\section{Acknowledgments}

We sincerely appreciate the participation of members and volunteers in collecting the initial data and the cooperation of the staff of the Red Crescent Society of Isfahan. We would also like 
to extend our deepest gratitude to the professors of the Islamic Azad University of Bushehr for their indispensable help and support.

\section{Conflict of Interests}

The authors have no conflict of interest to declare.

\section{References}

1. Mafi A, Namvar H. Investigating the factors affecting the social participation of citizens in urban development and management. The Second National Conference on Modern Management Sciences and Sustainable Planning in Iran, Tehran, Iran; 2016. [In Persian].

2. Feirosmand M, Rajabi A, Lahimian R. The role of social participation in sustainable urban development (Case study: Chalous city). $2^{\text {nd }}$ International Conference on Modern Research in civil Engineering, Architectural and Urban Management and Environment, Karaj, Iran; 2018. [In Persian].

3. Bostan Z, Bakhshi H. Studying the effective factors of attracting and maintaining volunteers in Red Crescent society of Khorasan Razavi. Quart Sci J Rescue Relief 2017; 9(2): 14-26. [In Persian].

4. Heydarkhani H, Nourbakhsh U, Ghanbari N. The relationship between religiosity and social health of young people in marginal areas of Kermanshah. Soc Dev Welfare Plan 2017; 8 (30): 31-66. [In Persian].

5. Mohammad Saleh T, Hourieh Rabbani I. The examination of the effective factors in women's participation in the voluntarily charitable activities. J Islam Soc Stud 2018; 24(2): 135. [In Persian].

6. Mousavi SN, Sepahvand R, Jafari S, Jafari A. Investigating the role of religiosity in trust and social participation of students of Lorestan University. Soc Cap Manag 2018; 5(4): 629-49. [In Persian].

7. Khaghanizadeh A, Khosravi S. Investigating the role of social capital on youth group participation in the activities of the Red Crescent population (Case study: 15-29 year olds in Tehran). The first national conference on lasting good (study and evaluation of good deeds in Iran), Tehran, Iran; 2016. [In Persian].

8. Heydari K, Ebrahiminejad M, Sadeghi Z. Investigating the role of public participation in improving the crisis management of the Red Crescent Organization (Case study of Chaharmahal and Bakhtiari province). National Conference on Crisis Management and HSE in Vital Arteries, Industries and Urban Management, Tehran, Iran;
2013. [In Persian].

9. Nowrouzi FE, Bakhtiari M. Social participation and its determining factors. Rahbord J 2010; 53(53): 249-69. [In Persian].

10. Vicheka L. Cambodian women and barriers to social participation. Cambodia: Cambodian University; 2005.

11. Bahry D, Silver BD. Soviet citizen participation on the eve of democratization. Am Political Sci Rev 1990; 84(3): 821-47.

12. Uslaner EM, Brown M. Inequality, trust, and civic engagement. Am Politics Res 2005; 33(6): 868-94.

13. Guth J, Green JC, Kellstedt LA, Smidt CE. Religion and political participation. Annual Meeting of the American Political Science Association, American Political Science Association, Washington, DC, USA; 2002.

14. Mehdikhani A. Political and economic development. $1^{\text {st }}$ ed. Tehran: Arun Publications; 2002. [In Persian].

15. Hoffman M, Dowd R. Religion gender and political participation in Africa: Lessons from Nigeria, Senegal, and Uganda. Notre Dame: Department of Political Science; 2008.

16. Fukuyama F. Social capital, civil society and development. Third World Quart 2001; 22(1): 7-20.

17. Glock CY, Stark R. Religion and society in tension: a publi. from the research program in the Sociology of Religion Survey Research Center, Univ. of Calif., Berkeley. Chicago: Rand McNally; 1970. 